\title{
Chapter 25 \\ Considering the Geological Disposal Program of High-Level Radioactive Waste Through Classroom Debate
}

\author{
Akemi Yoshida
}

\begin{abstract}
Although nuclear power has become recognized as a social issue-one that concerns us all-there is still, in Japan, insufficient public debate on the problems posed by this form of energy. In particular, interest among the younger generation on this and many other issues is limited, a situation reflected in the low turnout of young people at elections. The disposal of high-level radioactive waste is an issue that cannot be simply solved by shutting down nuclear reactors. Yet, in spite of the need to urgently find a solution to the problem of nuclear waste, many young people appear to be apathetic. Part of the reason for this lack of interest is that students majoring in the so-called humanities do not feel confident approaching the issue. As a way to raise such students' interest in the issue of nuclear waste disposal, debating courses were held in the social science departments of two universities located in Aichi Prefecture, Japan. This chapter reports on these courses, discusses the value and effectiveness of debate in raising awareness of social issues, and assesses potential problems with implementing debating in educational contexts.
\end{abstract}

Keywords Active learning $\bullet$ Classroom debate $\bullet$ Communication training $\bullet$ Fundamental literacy for members of society $\bullet$ Nuclear power $\bullet$ Radioactive waste

\subsection{Introduction}

\subsubsection{The Situation Now}

Although the problems surrounding nuclear power have certainly become a social issue, it cannot be said that the present discussion on this issue is always calm and rooted in science. Elsewhere in the world, including in the USA and various European countries, the importance of public debate has been emphasized and reports published on the efficacy of specific examples. In Japan, however, particularly since the Fukushima Daiichi nuclear accident, sensational media reporting

\footnotetext{
A. Yoshida $(\bowtie)$

Sugiyama Jogakuen University, 3-2005 Takenoyama, Nissin-City, Aichi, Japan

e-mail: ayoshida@sugiyama-u.ac.jp 
has not served to encourage sound debate on the issue of nuclear power. Moreover, this is not limited to the issue of nuclear power, nor is it a phenomenon that dates from the Fukushima disaster: issues around food safety and gender equality have been similarly characterized by emotive media reporting. Debate around these issues has not been informed by current scientific knowledge; indeed, what has prevailed is argument based on emotion engaged in without even an understanding of the relevant laws.

Being a democratic society entails that the path society follows is set according to the wishes of its citizens. These citizens exchange their divergent views and do their utmost to reach a consensus. If an agreement cannot be reached, society acts in accordance with the opinion of the majority. Necessary for such a process is that people think about an issue and express their views. In modern society, however, because many issues are complicated and difficult for people to adequately understand, often such issues are left to the "experts."

Although the citizens' right of self-determination should go hand in hand with responsibility, entrusting decision making to the experts has resulted in responsibility for these decisions being thrust upon them. Entrusting all responsibility to the experts could be expected to expedite decision making, but this has not been the case; instead, the emotional response of the public has contributed further to the deferring of decision making.

\subsubsection{Why has Such a Situation Occurred?}

One reason is that expressing one's opinion is not necessarily viewed in a favorable light at school and in the home. The way of thinking in Japan, encapsulated in the saying wa wo motte totoshi (harmony is of utmost importance), leads to virtue being placed on conforming to the views of others rather than asserting one's own opinions. It is partly because of this feeling that Japanese people in general have had relatively little practice in expressing their ideas and opinions to others. In recent years, debate-based lessons have been introduced by some elementary schools, but the spread of such lessons through elementary school education as a whole has not been sufficient. The second reason is rooted in the pivotal role given at the elementary level to sakubun, or essay writing. Pupils practice exploring their emotions and putting them down on paper, but not how to think in a logical way and support their opinion with evidence. A third reason given for the situation described here is the complexity of social problems nowadays, making understanding difficult for "ordinary people," who just give up even thinking about the issue.

The more complex issues become, however, the greater the necessity for citizens to engage in discussion, express their opinions, and then make decisions. It is, therefore, incumbent on each citizen to grapple with and discuss such issues. Judging from the present situation, it does not seem that staging public debates, having experts offer explanations, or other simple methods can serve as a substitute for real engagement by the citizens. Although workshops aimed at citizens have 
been held, it is doubtful that participation in debates that occur in such forums is built on a sufficient understanding of the issue at hand. There also appear to be cases when debate is based only on information that fits the administration's agenda. The information is simplified, and any exchange of views is debate in name only, without substance. It is necessary to look for effective ways to discuss issues to make such workshops and public debates productive and to change the explanatory meetings from superficial gesturing into something more substantive.

Moreover, in spite of the fact that many of the social problems we face are not just a concern for now, but also for the future, many of those interested in social issues and who vote in elections are elderly. Listening to the voices of the elderly is, of course, important, but, for a healthy democracy, it is necessary for young people to engage in debate and be involved in making decisions that affect their society. But how can such engagement by young people be promoted? The way that the author would like to suggest in this chapter is through debating lessons in school.

In a narrow sense, debate can be defined as follows: "discussion on a specific issue involving two groups of speakers, with one group taking a position of supporting the topic and the other arguing against it. Each of the groups seeks to persuade a third party." [1] (e.g., Yomiuri Shimbun 2013:2). Many of the topics for discussion are chosen from policy issues. To encourage participants to approach an issue from new and multiple perspectives, they are allocated (usually by the teacher) to either one of the groups, that is, they do not choose for themselves which side of the issue to support. This chapter describes a case study of a debating course, taught by the author, and examines its effects and any issues that emerged. Aimed at undergraduate students in a university, the topic of debate in the course was "the problem of high-level atomic waste disposal."

\subsubsection{Deciding the Topic}

The founding of the All Japan Educational Debate Association, of which the author is a committee member, was the catalyst for a national debating contest, which was started in the Tokai, or central region, of Japan. This contest, having been sponsored for some years by Chubu Electric Power Company, debates energy-related issues. High school students have faced each other over topics such as "Japan should abandon nuclear power: for or against?"; "Television broadcasting time in Japan should be limited to save energy: for or against?" Although the topic of energy, as well as many other policy issues, needs to be thought about by the next generation, it is just such issues that the younger generation does not appear eager to tackle face on. This is where debate, with its game-like, competitive element can serve an important role. In the context of debate, young people have been shown to engage seriously with such issues.

With this in mind, the author organized a debate for her class of university students. They debated the following motion, suggested originally by Chiba University's Assistant Professor, Daisuke Fujikawa: Japan should scrap the plan 
to store high-level radioactive waste underground: Do you agree or disagree? ${ }^{(1)}$ This paper describes the procedure of the debate in the classroom, assesses its effectiveness, and discusses certain problems that emerged from this activity.

\subsection{Research Method}

In 2013, the author compared and examined debate-focused courses held in two universities located in Aichi, central Japan; details of the courses are as follows.

1. "Enshu 1" (Seminar 1), a first-semester course, was taught to third- and fourthyear students at Sugiyama Jogakuen University's Department of Human Sciences.

2. "Introduction to debate," a first-semester course, was taught to second- and third-year students at Aichi Shukutoku University's Faculty of Global Culture and Communication.

3. "Introduction to debate," this time a second-semester course, was taught to second- and third-year students at Aichi Shukutoku University's Faculty of Global Culture and Communication.

By studying these classes, the author hoped, first, to elucidate how students understanding of the debate issue - the disposal of high-level radioactive wastewould be affected by the lessons; and, second, to assess the effectiveness of debating classes on issues related to natural science facing modern society. In addition, students completed a questionnaire, "Fundamental Literacy for Members of Society" (2). Through analysis of the results of this survey, the author sought to gain new insights into methodology to promote a deeper understanding among students of issues facing modern society.

The course as listed here had four main features. First, the theme of the debate was announced at the beginning of the course. Second, rather than having students choose the subject for debate, the topic was assigned to the students. The fact that the topic was a science-related one was the third feature of the course. Because the students were from a humanities/social sciences background, their basic knowledge of science was, on the whole, rather limited. Because there was some concern that students would not be able to cope with debate, efforts were made to deepen students' understanding of the issues involved before the actual debating contest. For example, Hajimu Yamana, professor at the Kyoto University Research Reactor Institute (KURRI), and Tomohisa Kakefu of the Japan Science Foundation were invited as guest speakers, and students also visited the Mizunami Underground Research Laboratory and the visitor facilities at Hamaoka Nuclear Power Station.

The fourth feature of the course was, therefore, that students were not left to research the topic by themselves, but were supported by, for example, being given the opportunity to listen and talk to experts. In addition, there was an element of experiential learning incorporated into the course in the form of, for example, the visit to Hamaoka Nuclear Power Station just mentioned. 


\subsubsection{Outline of the Courses}

(a) "Enshu I" (Seminar 1) comprised the following lessons:

Lesson 1: Orientation

Lessons 2-5: Discussion of selected readings from a 2009 book (“Buraika Suru Onatachi" [The Making of the Rowdy Women]) that was unrelated to the theme of the debate.

Lessons 6-8: Entitled "Introduction to debate," these lessons covered the theory and practice of debating, including debating techniques.

Lesson 9: Visit to Mizunami Underground Research Laboratory.

Lesson 10: Lecture on "High-level radioactive waste" by Hajimu Yamana (see above).

Lesson 11: Lecture on the geological disposal of radioactive waste by a member of staff of NUMO (the Nuclear Waste Management Organization of Japan).

Lesson 12-13: Preparation for debate.

Lesson 14-15: Staging of a debating contest.

In addition, during the course (on June 29, 2013) students toured visitor facilities at Hamaoka Nuclear Power Station in Shizuoka Prefecture.

Yoshida [2] (Yoshida, A. 2014:123)

(b) "Introduction to debate" comprised the lessons shown below.

Lesson 1: Orientation

Lessons 2-5: Entitled "Introduction to debate," these lessons covered theory and practice of debating, including debating techniques.

Lesson 6: Lecture on the geological disposal of radioactive waste by a member of staff of NUMO (the Nuclear Waste Management Organization of Japan).

Lesson 7: Lecture on "High level radioactive waste" by a guest speaker, Hajimu Yamana, of KURRI (see above).

Lesson 8: Focus on geological disposal of radioactive waste

Lesson 9-10: Students engaged in "communication training."

Lesson 11-12: Preparation for debate.

Lesson 13-15: Staging of a debating contest.

During the course students were taken to Mizunami Underground Research Laboratory (June 22) and to the visitor facilities at Hamaoka Nuclear Power Station (June, 29).

Yoshida [2] (Yoshida, A. 2014:123)

(c) The second semester "Introduction to debate" course comprised the following 11 lessons:

Lesson 1: Orientation 
Lessons 2-3: Entitled "Introduction to debate," these lessons covered the theory and practice of debating, including debating techniques.

Lesson 4: Visit to Hamaoka Nuclear Power Station in Shizuoka Prefecture.

Lessons 5-6: Entitled "Introduction to debate 2," in these classes students participated in a model debate and watched a DVD of the debating competition held in the first semester.

Lesson 7: Lecture on the geological disposal of radioactive waste by a member of staff of NUMO (the Nuclear Waste Management Organization of Japan).

Lesson 7-8: Students engaged in "communication training."

Lesson 9: Tomohisa Kakefu gave a talk on radiation, which incorporated demonstrations.

Lesson 10: Lecture on the geological disposal of radioactive waste by a member of staff of NUMO (the Nuclear Waste Management Organization of Japan).

Lesson 11: Visit to Mizunami Underground Research Laboratory.

\subsection{Reflections on the Courses}

In each of the courses, the students reached a level that enabled them to maintain a debate during the competition held during at the end of the course. Owing in large part to Fujikawa's well-constructed topic, the debate proved to be a balanced one, with the result of the debate not overly biased either for or against the proposition.

Perhaps because of their humanities/social sciences background, the students had little background knowledge of radiation. Regarding the storage pool for spent nuclear fuel, for example, a number of students mistakenly thought that the spent fuel was dissolved in the water of the pool (the spent fuel is stored in the form of solid rods). However, because preparing for a debate necessitates clarifying which areas of one's understanding are lacking, students' grasp of the subject area gradually improved as the course progressed. During the period of the course various news stories appeared in the press related to nuclear power and NUMO. Students not only responded to this news in class, but also actively gathered information reported in the media, and were able to use such up-to-date information in the debate competition.

Despite the fact that nuclear power was an issue directly related to the provision of energy for their lives, some considered that nuclear energy concerned no more than Fukushima; in other words, their awareness of nuclear power as an issue pertinent to them was low. However, through doing the course, students' understanding deepened and they also began to appreciate that the issue was one that directly affected them.

The input from experts was also important for helping students to understand the issues. At the beginning of the course, there were students who, not understanding fundamental facts - for example, the difference between radial rays and radioactivity_practically "gave up thinking" about the issues. However, with the tuition of 
the guest speakers and their demonstrations of a cloud chamber (a simple device that allows the decay of radioactive materials to be observed) and other experiments, students gradually learned more about the science involved, leading them to become more proactive in thinking about issues for themselves.

\subsection{Results of the Questionnaire Survey}

The results of the "Fundamental literacy for members of society" questionnaire are summarized in this section. Responses were obtained from a total of 42 students (Enshu I): responses from 10 of the 12 students registered for the course; Introduction to Debate (first semester): 26 of the 27 students; Introduction to Debate (second semester): 6 of the 8 students. The composition of the classes was as follows: Enshu 1: third- and fourth-year female students; Introduction to Debate (first semester) and Introduction to Debate (second semester): second- and third-year female and male students. Because the sample was small, no comparison of data based on gender and year of study was made; instead, the results of the group as a whole is shown (see Fig. 25.1 and Table 25.1).

To gain a firm understanding of the disposal of high-level radioactive waste, and to be able to consider the issues, requires specialist knowledge as well as critical and logical thinking skills. In this respect, the overall results of the questionnaire were positive, but the scores were particularly high for items

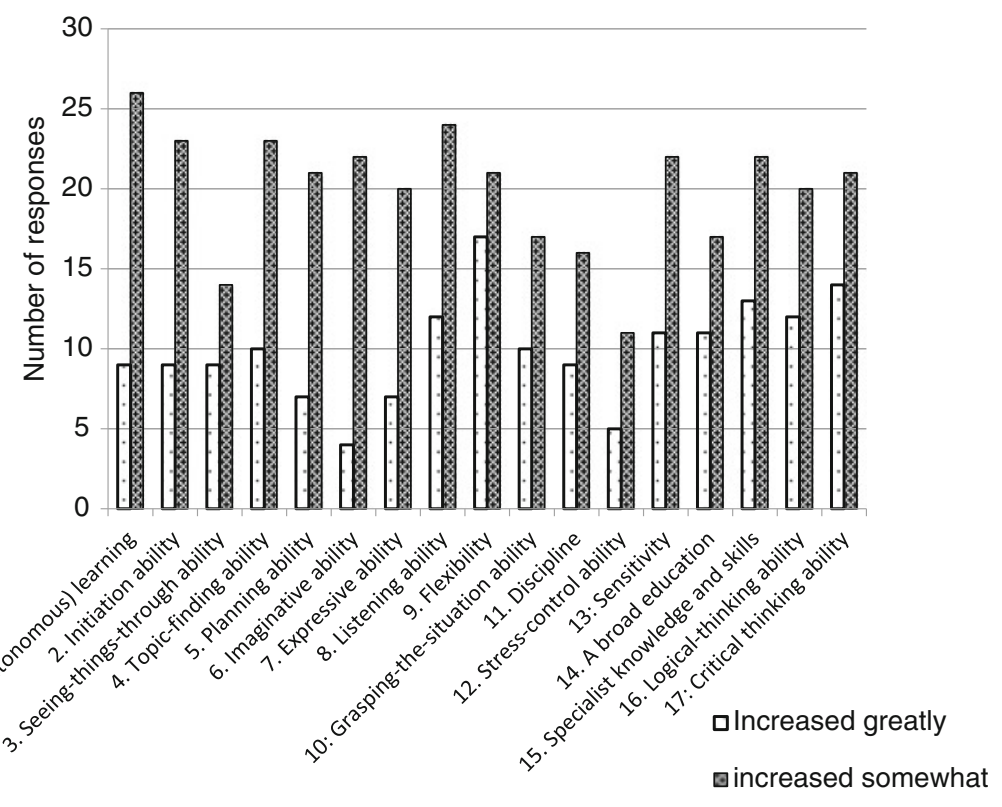

Fig. 25.1 Responses that indicated an increase in fundamental social-literacy skills 
Table 25.1 The fundamental social-literacy skills gained through this course

\begin{tabular}{l|l|l|l|l|l|l}
\hline & $\begin{array}{l}\text { Increased } \\
\text { greatly }\end{array}$ & $\begin{array}{l}\text { Increased } \\
\text { somewhat }\end{array}$ & $\begin{array}{l}\text { No } \\
\text { change }\end{array}$ & $\begin{array}{l}\text { Slight } \\
\text { decrease }\end{array}$ & $\begin{array}{l}\text { Decreased } \\
\text { greatly }\end{array}$ & $\begin{array}{l}\text { No } \\
\text { response }\end{array}$ \\
\hline $\begin{array}{c}\text { 1. Independent } \\
\text { (autonomous) } \\
\text { learning }\end{array}$ & 9 & 26 & 7 & 0 & 0 & 0 \\
\hline 2. Initiation ability & 9 & 23 & 10 & 0 & 0 & 0 \\
\hline $\begin{array}{l}\text { 3. Seeing-things- } \\
\text { through ability }\end{array}$ & 9 & 14 & 19 & 0 & 0 & 0 \\
\hline $\begin{array}{l}\text { 4. Topic-finding } \\
\text { ability }\end{array}$ & 10 & 23 & 9 & 0 & 0 & 0 \\
\hline 5. Planning ability & 7 & 21 & 13 & 0 & 0 & 1 \\
\hline $\begin{array}{l}\text { 6. Imaginative ability } \\
\text { 7. Expressive ability }\end{array}$ & 4 & 22 & 16 & 0 & 0 & 0 \\
\hline 8. Listening ability & 12 & 20 & 15 & 0 & 0 & 0 \\
\hline 9. Flexibility & 17 & 24 & 6 & 0 & 0 & 0 \\
\hline $\begin{array}{l}\text { 10. Grasping-the-situ- } \\
\text { ation ability }\end{array}$ & 10 & 17 & 4 & 0 & 0 & 0 \\
\hline 11. Discipline & 9 & 16 & 15 & 0 & 0 & 0 \\
\hline $\begin{array}{c}\text { 12. Stress-control } \\
\text { ability }\end{array}$ & 5 & 11 & 25 & 1 & 0 & 0 \\
\hline 13. Sensitivity & 11 & 22 & 9 & 0 & 0 & 0 \\
\hline 14. A broad education & 11 & 17 & 14 & 0 & 0 & 0 \\
\hline $\begin{array}{l}\text { 15. Specialist knowl- } \\
\text { edge and skills }\end{array}$ & 13 & 22 & 7 & 0 & 0 & 0 \\
\hline $\begin{array}{l}\text { 16. Logical thinking } \\
\text { ability }\end{array}$ & 12 & 20 & 10 & 0 & 0 & 0 \\
\hline $\begin{array}{l}\text { 17. Critical thinking } \\
\text { ability }\end{array}$ & 14 & 21 & 7 & 0 & 0 & 0 \\
\hline
\end{tabular}

15, 16, and 17 (that is, Specialist knowledge and Skills, Logical thinking Ability, and Critical thinking ability). The results overall indicated that debate can be an effective activity for shedding light into, and for examining, social issues that require specific background knowledge and judgment.

\subsection{Issues for the Future}

The results of this study suggest that when dealing in class with social issues such as the disposal of high-level radioactive waste that require a certain level of basic scientific knowledge, debate and other kinds of active learning may be more effective than lecture-style, noninteractive pedagogical methods. When implementing active learning, however, time and cost and many other factors need to be considered. For the courses described in this chapter, the author was 
able to gain the cooperation of NUMO, which made it possible for her to integrate into the course lectures by experts and visits by students to relevant facilities. But when such outside help cannot be obtained, alternatives must be considered.

To take debate on social issues beyond the walls of the university classroom, a DVD of the 2013 students' debate competition may be a valuable resource that could be shown to the general public. In addition, there is a need for a more conducive learning environment for the debating, which could perhaps be achieved by creating scenarios for model debates and organizing workshops.

This course also pointed to the need for consumer education. It is important to not only think about the short-term consequences of the things we use and their disposal, but also to consider from a global perspective how our consumption will affect future generations. In debate for education, it is important to tackle a range of social issues from multiple points of view. In debating the issue of radioactive waste, in particular, it must be conveyed to students that the issue is not one that is solved just by shutting down nuclear reactors; whether or not we use nuclear energy in the future, the waste has already been produced, a by-product of our consumption.

This chapter has focused on courses aimed at undergraduate students. If possible, in the future, the author would like to run similar debating courses with middleand high-school students and with adults, and then assess, as was done in this study, the impact of debate as an educational activity.

\subsection{Notes}

1. Professor Daisuke Fujikawa, with the support of NUMO (as was had in this present study), conceived this theme for a debate held in 2012 for undergraduate students on a teacher-training course at Chiba University [3] (Fujikawa, D.2013:5).

2. Sugiyama Jogakuen University, the university to which the author is affiliated, is a participant in a project supported financially by the Ministry of Education, Culture, Sports, Science and Technology. Called the "Project of Educational Reform and Structural Improvement to Respond to the Needs of Industry," it is composed of 23 universities (including junior colleges) in the central region of Japan. As part of the project, each university engages in career education, and Sugiyama Jogakuen University for its part has focused on active learning to raise its educational performance. The "Fundamental Literacy for Members of Society Questionnaire" was implemented as part of this effort to effectively utilize active learning. The questionnaire consisted of the following 17 items, together with a short definition.

1. Independent (autonomous) learning: The capacity to engage in an activity on one's own volition.

2. Initiation ability: Appealing and encouraging others to become involved.

3. Seeing-things-through ability: The capacity to set a target and act to achieve it.

4. Topic-finding ability: The capacity to analyze the situation and clarify aims and issues. 
5. Planning ability: The capacity to clarify the process that can lead to a solution; the ability to plan.

6. Imaginative ability: The capacity to create new value.

7. Expressive ability: The capacity to convey your views clearly in an easily understandable way.

8. Listening ability: The capacity to listen attentively to what the other person is saying.

9. Flexibility: The capacity to understand other people's opinions and positions.

10. Grasping-the-situation ability: The capacity to understand the relationship between you and the people and the situation around you.

11. Discipline: The capacity to follow society's rules and keep promises made with others.

12. Stress-control ability: the capacity to respond appropriately to sources of stress.

13. Sensitivity: The capacity to respond to stimulus from the external environment.

14. A broad education: The possession not just of knowledge, but also an ability to understand and process knowledge creatively.

15. Specialist knowledge and skills: The possession of in-depth knowledge and skills in a particular academic or other field.

16. Logical thinking ability: the capacity to think coherently and logically.

17. Critical thinking ability: the capacity to analyze and judge the suitability and validity of issues and arguments.

Sugiyama Jogakuen University [4] (Sugiyama Jogakuen University 2013) Sugiyama Jogakuen University et al. [5] (Sugiyama Jogakuen University, Special Committee on Career Education, Whole-Faculty Faculty Development Committee 2013)

Open Access This chapter is distributed under the terms of the Creative Commons Attribution Noncommercial License, which permits any noncommercial use, distribution, and reproduction in any medium, provided the original author(s) and source are credited.

\section{References}

1. Shimbun Y, The All Japan Educational Debate Association (2013) Dibeeto koshien staartobukku (The Startbook for the National Debating Competition for Junior and Senior High Schools). http://nade.jp/files/uploads/startbook2013.pdf/. Accessed 12 December 2013

2. Yoshida A (2014) Possibility of debate class as active learning in University. Ningenkankeigakukenkyu. (Research Journal of the Department of Human Relations), No. 12, Sugiyama Jogakuen University

3. Fujikawa D (2013) Kyoinkeidaigaku ni okeru dibeito jugyou ni oite gendaiteki torikumi wo okonau kokoromi: koureberu houshyasei haikibutsu no shori mondai wo toriagete (An attempt to deal with a contemporary issue in a debate education class of faculty on teacher training. 
On the issue of high-level radioactive waste management). Project Report of the Chiba University School of Humanities and Social Sciences

4. Sugiyama Jogakuen University (2013) Shakaijin kisoryoku ni kansuru ankeeto no onegai. (Request to complete "Fundamental literacy for members of society" questionnaire)

5. Sugiyama Jogakuen University, Special Committee on Career Education, Whole-Faculty Faculty Development Committee (2013) Shakaijin kisoryoku to akutibu raaningu ni kansuru ankeeto chosa kaitou youshi. (Response sheet for the questionnaire survey on fundamental literacy for members of society and active learning) 